\title{
VILJOJEN MYKOTOKSIINIT SUOMESSA
}

Veli Hietaniemi $^{1)}$, Sari Rämö ${ }^{1)}$, Tauno Koivisto ${ }^{1)}$, Timo Pitkänen ${ }^{2)}$ ja Elise Ketoja ${ }^{2)}$, MTT, Mirja Kartio $^{3)}$ ja Kaija Varimo ${ }^{3)}$, Evira ja Sari Peltonen ${ }^{4)}$, Pro Agria

${ }^{1)}$ MTT Laboratoriot, 31600 Jokioinen, veli.hietaniemi@mtt.fi, sari.ramo@mtt.fi, tauno.koivisto@mtt.fi

${ }^{2)}$ MTT Tietohallinto,31600 Jokioinen, timo.pitkanen@mtt.fi,elise.ketoja@mtt.fi

${ }^{3)}$ Evira, FI-00790 Helsinki,mirja.kartio@evira.fi, kaija.varimo@evira.fi

4) Pro Agria, FI-01301Vantaa, sari.peltonen@proagria.fi

\section{Tiivistelmä}

MMM:n johtama viljojen turvallisuustietojen seuranta vuosina 1999 ... 2006 toteutti kansallisen viljastrategian päämääriä. Viljastrategiassa korostettiin viljantuotannon kannattavuuden ja kilpailukyvyn parantamista, laadun kehittämistä ja lisäarvon luontia laatuketjuun. Turvallisuustietoseuranta kohdistui viljojen hometoksiineihin, raskasmetalleihin ja torjunta-ainejäämiin. Pääasiassa seurantatutkimus keskittyi viljojen Fusarium -toksiineihin. Tutkimus toteutettiin Eviran, Pro Agrian ja MTT:n yhteistyönä.

Turvallisuustietoseurannan keskeisiä tavoitteita oli hometoksiinipitoisuuksien seurannan lisäksi viljanäytteiden viljelytekniikka- ja viljelyolosuhdetietojen ja hometoksiinipitoisuuksien syyseuraussuhteiden analysointi. Näytteiden taustatietoja kerättiin koko tutkimuksen ajan maalajeista, lajikkeista, typpilannoituksesta, siemenen laadusta, esikasveista, viljelykierrosta, kasvinsuojelutoimenpiteistä, kasvuajasta, korjuukosteudesta, kuivauksesta ja sadon määrästä.

Turvallisuustietoseurannan tulosten perusteella kevätviljat olivat alttiimpia Fusarium -sienten tartunnalle ja toksiinien muodostumiselle. Syysviljojen hometoksiinipitoisuudet olivat koko seurantajakson hyvin alhaisia ja pääasiassa alle määritysrajojen. Kaikista tutkituista viljanäytteistä $(991 \mathrm{kpl})$ vuosina 1999 ... 2006 EU -raja-arvon ylittäviä pitoisuuksia DON:n osalta oli 18 kpl. Mikäli tarkastellaan ainoastaan kauranäytteiden DON -pitoisuuksia, raja-arvon $1750 \mu \mathrm{g} / \mathrm{kg}$ ylityksiä oli $11 \mathrm{kpl}$ tutkituista 279 näytteestä. Kauranäytteistä lastenruoan raja-arvon $200 \mu \mathrm{g} / \mathrm{kg}$ alittavia näytteitä oli $164 \mathrm{kpl}$. Kaura oli viljoistamme selvästi herkin Fusarium -tartunnalle ja toksiinien muodostumiselle. Lisäksi rehuohralla ja kevätvehnällä havaittiin raja-arvon ylityksiä.

Hometoksiinien hallinnassa tärkeintä oli siemenen kunnostus ja peittaus, viljelykierto, sadonkorjuun ajoitus ja viljan kuivaus. Myöhäinen lajike lisäsi toksiiniriskiä, koska kasvukauden venyminen pitkälle loppukesään lisää epävarmuutta sadonkorjuuajan säästä. Lakoontuneessa kasvustossa riski hometoksiinien muodostumiseen kasvoi. Viljan huolellinen lämminilmakuivaus alle 14 \%:iin myös hyvinä vuosina oli parhaita keinoja hallita hometoksiiniriski.

Turvallisuustietoseurannan tuloksia hyödynnettiin monin eri tavoin viljaraaka-aineen turvallisuutta arvioitaessa, viljan hyvät tuotanto- ja varastointitavat ja punahomeet viljassa -oppaassa, yritysten omavalvonnassa, neuvonnassa, valvonnassa, riskin arvioinnissa ja uusien tutkimuskohteiden valinnassa. Fusarium -toksiinien seurannasta muodostui aikavälillä 1999 ... 2006 vilja-alan toimijoiden yhteinen hanke, joka jatkuu edelleen ja kehittyy asiakkaiden tarpeiden mukaan.

Asiasanat: Fusarium -toksiinit, DON, T-2, HT-2, viljat, turvallisuustietoseuranta, syy-seuraussuhteet 


\section{Johdanto}

MMM:n johtama viljojen turvallisuustietojen seuranta vuosina 1999 .. 2006 on toteuttanut kansallisen viljastrategian päämääriä. Niissä korostetaan viljantuotannon kannattavuuden ja kilpailukyvyn parantamista, laadun kehittämistä ja lisäarvon luontia laatuketjuun. Turvallisuustietoseuranta on kohdistunut viljojen hometoksiineihin, raskasmetalleihin ja torjunta-ainejäämiin. Pääasiassa seurantatutkimus on keskittynyt viljojen Fusarium -toksiineihin, ja sitä on toteutettu Eviran, Pro Agrian ja MTT:n yhteistyönä vuodesta 1999. Tutkimuksen keskeisiä tavoitteita on ollut toksiinipitoisuuksien seurannan lisäksi viljanäytteiden viljelytekniikka- ja viljelyolosuhdetietojen ja hometoksiinipitoisuuksien syyseuraussuhteiden analysointi. Näytteiden taustatietoja on kerätty koko tutkimuksen ajan maalajeista, lajikkeista, typpilannoituksesta, siemenen laadusta, esikasveista, viljelykierrosta, kasvinsuojelutoimenpiteistä, kasvuajasta, korjuukosteudesta, kuivauksesta ja sadon määrästä.

Viljojen turvallisuustietoseurannan tuloksista on vuosittain raportoitu MMM:n vilja-alan yhteistyöryhmälle (VYR), vilja-alan asiantuntijatyöryhmille sekä laatujohtoryhmälle. Tulokset ovat olleet käytettävissä myös riskien hallinnan arvioinnissa. Turvallisuustietoseurannan tähänastisten tulosten perusteella tärkeimmät Fusarium -toksiinien hallintakeinot ovat seuraavat: viljelykierto, lajikevalinta, siemenen kunnostus ja peittaus, sadonkorjuun ajoitus ja viljan huolellinen kuivaus. Myöhäinen lajike lisää toksiiniriskiä, koska kasvukauden venyminen pitkälle loppukesään lisää epävarmuutta sadonkorjuun säästä. Lakoontuneessa kasvustossa riski hometoksiinien muodostumiseen kasvaa. Viljan huolellinen lämminilmakuivaus alle $14 \%$ :iin myös hyvinä vuosina ja lajittelu on parhaita keinoja minimoida hometoksiiniriski. Hometoksiinien hallinnassa korostuu ammattitaitoinen viljely.

Turvallisuustietoseurannan tuloksia on monin tavoin hyödynnetty viljaraaka-aineen turvallisuutta arvioitaessa, viljan hyvät tuotanto- ja varastointitavat ja punahomeet viljassa -oppaassa, yritysten omavalvonnassa, neuvonnassa, valvonnassa, riskin arvioinnissa ja uusien tutkimuskohteiden valinnassa. Fusarium -toksiinien seurannasta on muodostunut vilja-alan toimijoiden yhteinen hanke, joka jatkuu edelleen ja kehittyy asiakkaiden tarpeiden mukaan.

\section{Aineisto ja menetelmät}

Kattavasti koko Suomea edustavat kaura-, rehuohra-, mallasohra-, kevätvehnä-, ruis- ja syysvehnänäytteet kerättiin vuosittain Eviran valtakunnallisen viljan laatututkimuksen yhteydessä. Näytteiden lukumäärä vaihteli 100 - $170 \mathrm{kpl}$ välillä niin, että vuonna 1999 näytemäärä oli $100 \mathrm{kpl}$, vuosina 2000 ... $2005120 \mathrm{kpl} \mathrm{ja} \mathrm{vuosina} 2006$... $2007170 \mathrm{kpl}$. Näytteistä analysoitiin Fusarium -sienten muodostamat toksiinit deoksinivalenoli (DON), 3 -asetyylideoksinivalenoli (3-AcDON), 15 -asetyylideoksinivalenoli (15 -AcDON), nivalenoli (NIV), fusarenon -X (F-X), T-2-, HT-2 -toksiini ja tsearalenoni sekä okratoksiini A, joka on varastotyyppisten homeiden, kuten Aspergillus ja Penicillium -sienien tuottama toksiini. Tsearalenonin ja okratoksiini A:n identifiointi ja kvantitointi suoritettiin HPLC:1lä ja muut edellä mainitut toksiinit GC-MS -tekniikalla. Toksiinianalyyseissä määritysalarajat olivat tsearalenonille $20 \mu \mathrm{g} / \mathrm{kg}$, okratoksiini A:lle $2 \mu \mathrm{g} / \mathrm{kg}$ ja muille $25 \mu \mathrm{g} / \mathrm{kg}$.

Evira vastasi näytteiden otosta, raskasmetalli- ja torjunta-ainemäärityksistä. MTT tuotti viljanäytteiden hometoksiinitulokset ja vastasi yhdessä Pro Agrian kanssa tulosaineiston syyseuraussuhteiden analysoinnista, tilastollisesta käsittelystä ja vuosiraporteista. Näytteenotto oli tarkasti ohjeistettu. Näytteitä lähettäneet viljelijät täyttivät myös viljelyn taustatietolomakkeen, jossa kysyttiin tärkeimmät lohkokohtaiset tiedot ja tehdyt viljelytoimenpiteet. Näytteiden otantaa tarkistettiin vuosittain painottamalla esimerkiksi näytteiden ottoa vuosina 2006 ja 2007 riskialttiiseen kauraan, ottamalla huomioon satokauden aikainen sadesumma ja sääolosuhteet sekä alueellinen edustavuus.

Tilastolliset tarkastelut T-2 + HT-2 ja DON -toksiinin osalta tehtiin eri menetelmillä. DON -pitoisuuksia mallitettaessa käytettiin regressiomallia, jossa oletettiin vastemuuttujan jakautumaksi normaalijakauma. Koska DON -pitoisuuden jakauma oli vino, tehtiin sille logaritmimuunnos (luonnollinen logaritmi). T-2 ja HT-2 toksiinien tilastollisessa analysoinnissa käytettiin niiden summaa. Summamuuttujan jakaumassa oli paljon 0 -arvoja, jonka vuoksi se luokiteltiin ja analysoitiin järjestysasteikollisena vasteena käyttäen proportional odds -mallia. 


\section{Tulokset ja tulosten tarkastelu}

Turvallisuustietoseurannan tulosten perusteella riskialttiimmat vuodet trikotekeeni B -tyypin toksiinien kuten deoksinivalenolin (DON) osalta olivat 1999, 2002, 2005 ja 2007 (taulukko 1). Vuotta 2002 leimasi keskikesän kuivuus ja vuotta 2005 loppukesän märkyys. Vuosi 2006 oli koko seurantajakson lämpimin ja vähäsateisin kasvukausi. Vuosi 2007 oli jälleen poikkeuksellinen, alkukasvukausi oli monin paikoin hyvin kuiva ja viljojen kukintavaiheesta alkaen saatiin sadetta tasaisesti ja melko runsaasti. Tämän vuoden lopulliset toksiinitulokset eivät vielä ole mukana tässä tarkastelussa muuta kuin suuntaa antavina tuloksina. Kuvassa 1 vuosien 1999 ... 2006 DON -toksiinitulokset on luokiteltu ottaen huomioon EU -säädöksen mukaiset korkeimmat sallitut enimmäismäärät prosessoimattomalle viljalle ja lastenruoan raaka-aineelle. EU -säädöksen mukaan elintarvikekäyttöön tarkoitetulla viljalla deoksinivalenolin raja-arvo on $1750 \mu \mathrm{g} / \mathrm{kg}$ prosessoimattomalla kauralla ja maissilla sekä muilla viljoilla $1250 \mu \mathrm{g} / \mathrm{kg}$. Lastenruoan viljaraaka-aineen DON -raja-arvo on $200 \mu \mathrm{g} / \mathrm{kg}$. Vastaavasti tsearalenonin enimmäismäärä prosessoimattomilla viljoilla on $100 \mu \mathrm{g} / \mathrm{kg}$ ja lastenruoan viljaraaka-aineella $20 \mu \mathrm{g} / \mathrm{kg}$. Raja-arvot koskevat kaikkea teollisuuteen myytävää elintarvikeviljaa. Rehuviljan sekä T-2 ja HT-2 -toksiinin vastaavat arvot ovat valmisteilla.

Taulukko 1. Yhteenveto viljan hometoksiiniseurannan vuosien 1999 .. 2006 keskimääräisistä DON -toksiinipitoisuuksista (mediaani).

\begin{tabular}{|l|c|c|c|c|c|c|c|c|}
\hline \multirow{2}{*}{ Viljalaji } & \multicolumn{7}{|c|}{ Keskimääräinen DON -pitoisuus (mediaani) eri vuosina } \\
\hline & v. 1999 & v. 2000 & v. 2001 & v. 2002 & v. 2003 & v. 2004 & v. 2005 & v. 2006 \\
\hline Ruis & $<50$ & $<50$ & $<25$ & $<25$ & $<25$ & $<25$ & - & $<25$ \\
\hline Syysvehnä & $<50$ & $<50$ & $<25$ & $<25$ & 28 & $<25$ & - & $<25$ \\
\hline Rehuohra & 105 & $<50$ & $<25$ & 214 & 87 & 35 & 250 & $<25$ \\
\hline Mallasohra & 60 & $<50$ & $<25$ & 50 & 29 & $<25$ & $<25$ & $<25$ \\
\hline Kevätvehnä & 58 & 136 & 27 & 117 & 47 & 69 & 77 & $<25$ \\
\hline Kaura & 326 & 98 & 90 & 264 & 226 & 115 & 170 & 135 \\
\hline keskimäärin & 74 & $<50$ & 26 & 95 & 56 & 32 & 110 & 25 \\
\hline
\end{tabular}

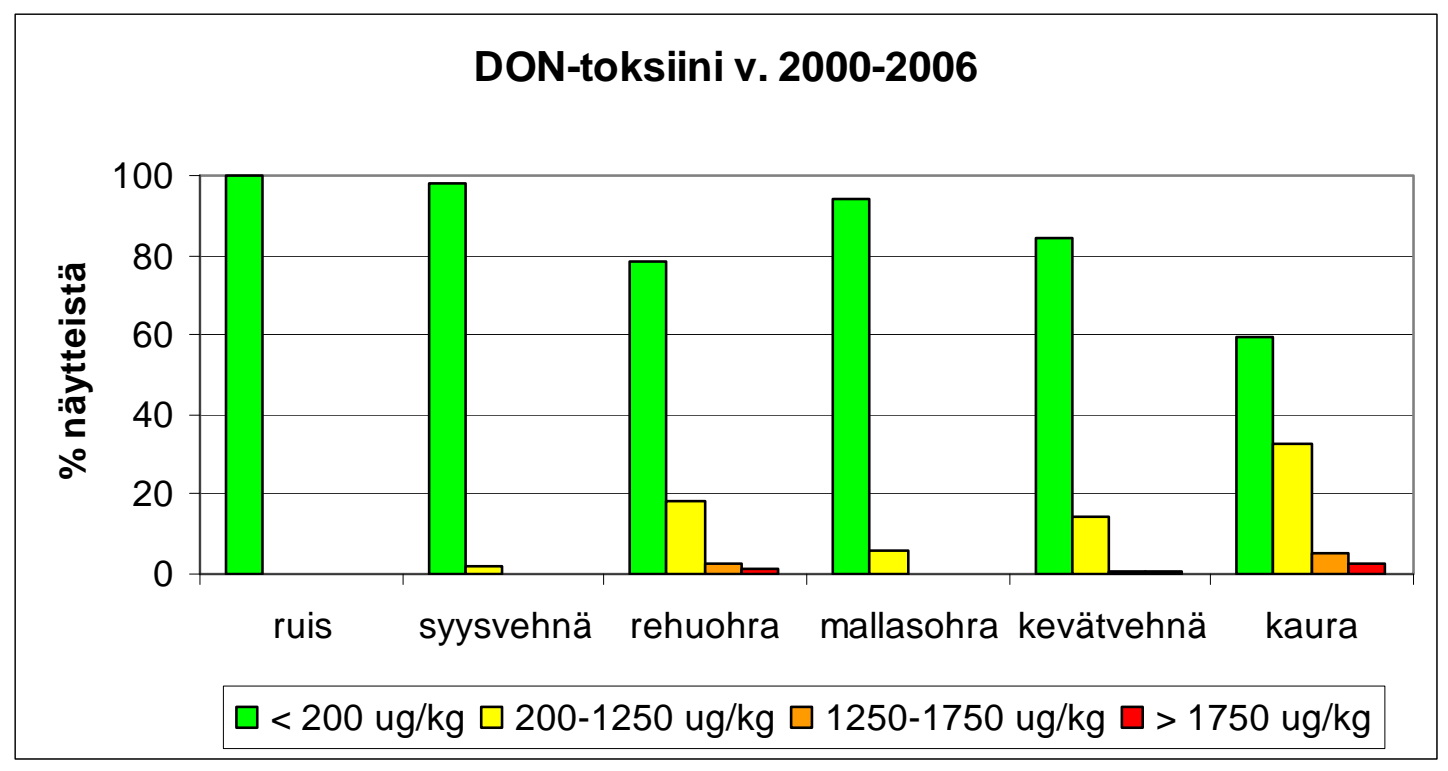

Kuva 1. Yhteenveto näytteiden DON -analyysitulosten jakautumisesta (\%) eri pitoisuusluokkiin eri viljalajeilla v. 2000 ... 2006 hometoksiinianalyyseissä. 
Tilastollisten tarkastelujen perusteella DON -pitoisuudet alenivat seurantavuosien aikana (Kuva 2). DON -toksiinin riski oli suurin pohjoisemmilla viljelyalueilla (Kuva 3). Alueellisuus yhdistettynä kylvösiemenen laatuun sekä hehtaarisadon ja lajikkeen yhdysvaikutus olivat tilastollisten tarkastelujen perusteella merkittävimpiä tekijöitä korkeiden DON -toksiinipitoisuuksien taustalla. Oman siemenen käytössä kunnostus ja peittaus alensivat toksiiniriskiä.

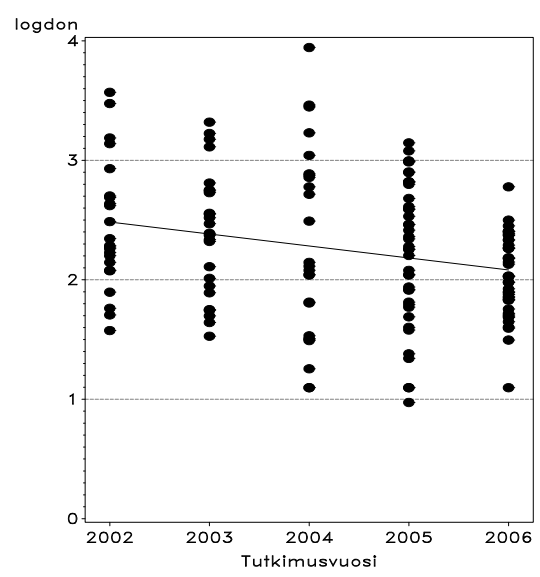

Kuva 2. Logaritminen DON -pitoisuus laskee lineaarisesti vuosien 2002 ... 2006 aikana.

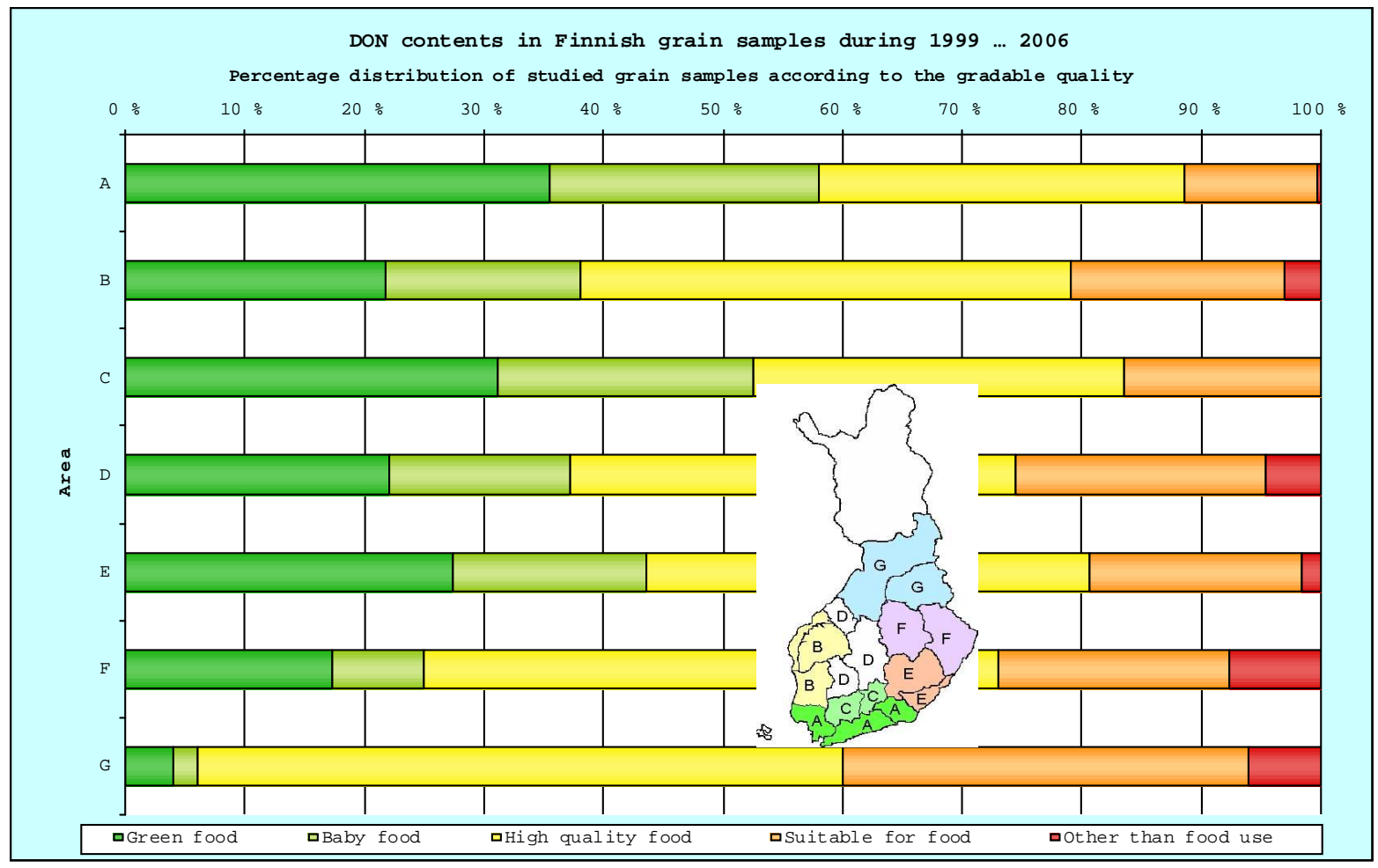

Kuva 3. DON -toksiinin pitoisuuksien (\% näytteistä) vaihtelu maantieteellisesti Suomessa seurantavuosien 1999 .. 2006 aikana. Merkkien selitykset: vihreä (ei havaittu), vaalean vihreä $(<200 \mu \mathrm{g} / \mathrm{kg})$, keltainen $(<500 \mu \mathrm{g} / \mathrm{kg})$, oranssi (alle elintarvikeraja-arvojen eli $<1250$ muut viljat paitsi kaura, $<1750 \mu \mathrm{g} / \mathrm{kg}$ kaura), punainen (pitoisuudet yli elintarvikeraja-arvojen).

Trikotekeeni A -tyypin yhdisteiden (T-2 ja HT-2 toksiinien) pitoisuudet kasvoivat viljasadossa tarkasteluajanjakson aikana (kuva 4). Vuodesta 2003 alkaen korkeita T-2 ja HT-2 -pitoisuuksia havaittiin säännönmukaisesti, erityisesti kaurassa (Kuva 4 ja 5). 


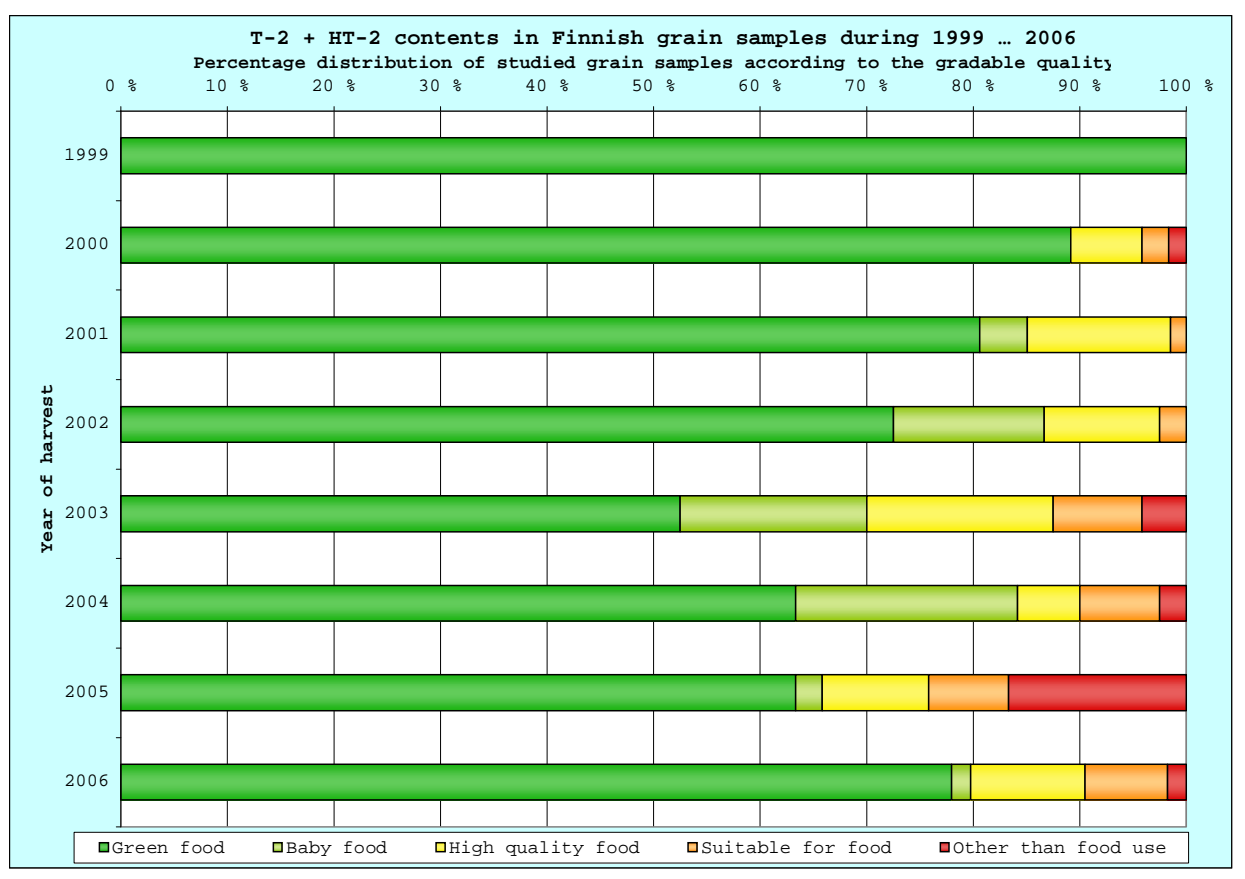

Kuva 4. T-2 ja HT-2 -toksiinien yhteispitoisuuksien määrä (\% näytteistä) Suomessa seurantavuosien $1999 .$. 2006 aikana. Merkkien selitykset: vihreä (ei havaittu), vaalean vihreä $(<50 \mu \mathrm{g} / \mathrm{kg})$, keltainen $(<200 \mu \mathrm{g} / \mathrm{kg})$, oranssi $(<500 \mu \mathrm{g} / \mathrm{kg})$, punainen $(>500 \mu \mathrm{g} / \mathrm{kg})$.

Näitä toksiineita esiintyi korkeina pitoisuuksina myös eteläisessä Suomessa (Kuva 5). Tilastollisissa tarkasteluissa kauran T-2 ja HT-2 toksiinien korkeita pitoisuuksia selittävät tekijät poikkesivat jonkin verran DON -toksiinin tuloksista. Siemenen laatu selitti tuloksia vain joinakin vuosina. Sen sijaan esikasvi vaikutti merkittävästi toksiinipitoisuuksiin: korkeimpia pitoisuuksia tavattiin enemmän yksipuolisessa viljanviljelyssä (kauran esikasvina kaura tai ohra). Lisäksi tuloksissa voitiin osoittaa lajikeherkkyyttä. Veli, Aslak ja Belinda -lajikkeissa korkeimpia pitoisuuksia tavattiin muita lajikkeita enemmän.

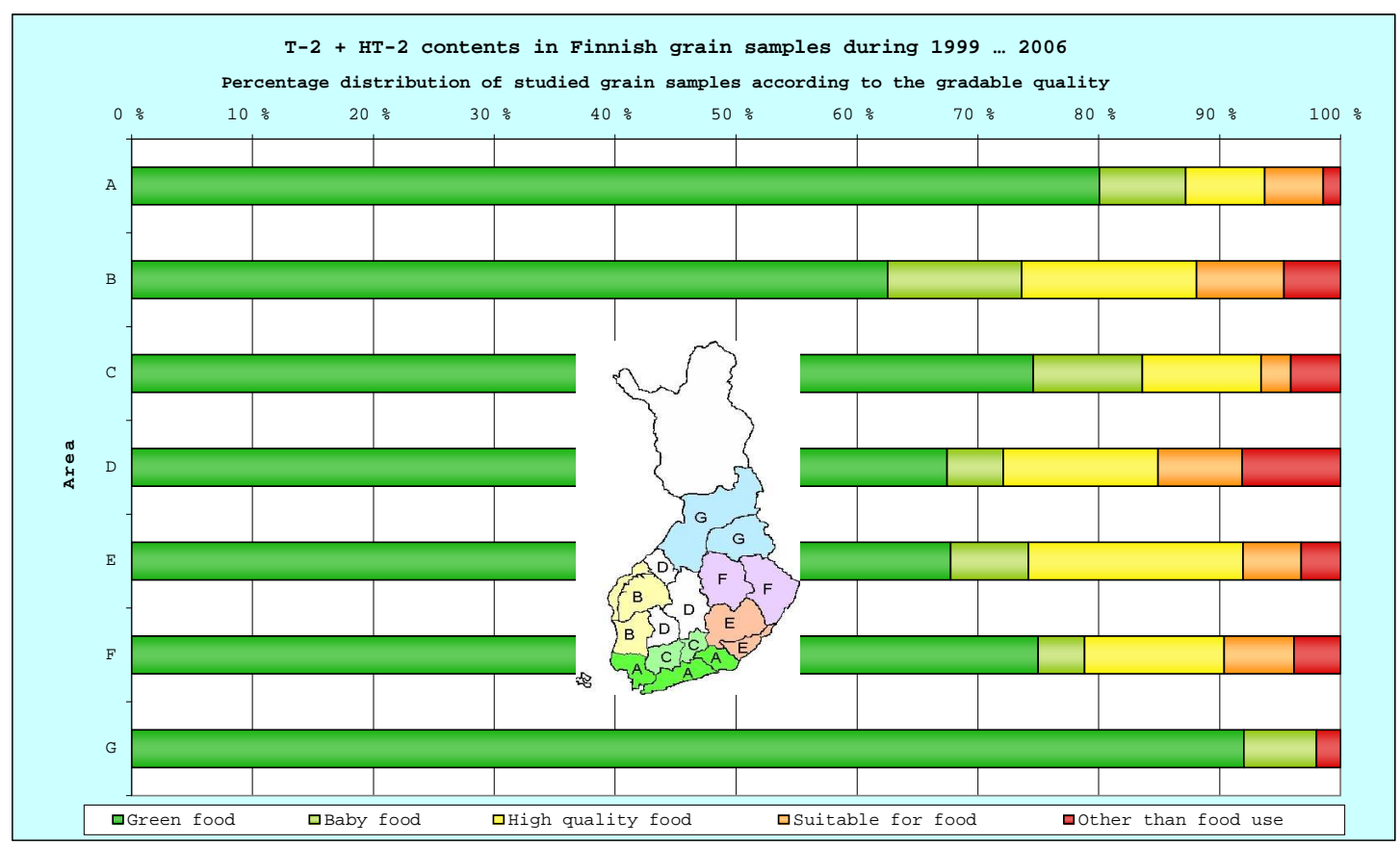

Kuva 5. T-2 ja HT-2 -toksiinien yhteispitoisuuksien (prosenttia näytteistä) vaihtelu maantieteellisesti Suomessa seurantavuosien 1999... 2006 aikana. Merkkien selitykset ovat kuten kuvassa 4. 
Maatalouden muutos viimeisen kymmenen vuoden aikana on ollut voimakasta ja viljelymenetelmät ovat muuttuneet. Yksipuolinen viljely on johtanut peltomaiden rakenteen heikkenemiseen, kevyen muokkauksen ja suorakylvön yleistymiseen. Fusarium -sienet ovat hyötyneet muokkauksen poisjättämisestä. Tähänastiset MTT:n tuottamat tutkimustulokset ovat osoittaneet, että kevytmuokkaus tai suorakylvö saattavat lisätä T-2 ja HT-2 toksiineja tuottavien sienten määrää ja sitä kautta toksiiniriskiä. MTT:n tutkimusten mukaan Fusarium -lajistossa on tapahtunut selkeitä muutoksia viimeisten 1020 vuoden aikana. 2000 -luvun alussa on esiintynyt kuivia ja lämpimiä kesiä ja punahomeiden lajikirjo on monipuolistunut verrattuna edellisen vuosikymmenen tilanteeseen. Uusi aikaisemmin tuntematon laji $F$. langsethiae löydettiin Suomesta vuonna 2001. Löydetty $F$. langsethiae -laji tuottaa jyviin jyvän kehityksen aikana T-2 ja HT-2 toksiineja. Kasvukauden kuivuus ja lämpö näyttävät suosivan lajin kasvumahdollisuuksia. Kotimaisista viljoista vuosina 1999... 2006 löydetyistä Fusarium -sienistä $F$. langsethiae oli yksi yleisimmistä. Lisäksi runsaasti esiintyi seuraavia Fusarium -sieniä: F. avenaceum, $F$. graminearum, $F$. culmorum, $F$. poae ja $F$. sporotrichioides. Tosin $F$. avenaceum ei tuota trikotekeeneja vaan moniliformiinia ja enniatiineja.

Turvallisuustietoseurannan tulosten perusteella kevätviljat ovat alttiimpia Fusarium -sienten tartunnalle ja toksiinien muodostumiselle. Syysviljojen hometoksiinipitoisuudet ovat olleet koko seurantajakson hyvin alhaisia ja pääasiassa alle määritysrajojen. Kaikista tutkituista viljanäytteistä $(991 \mathrm{kpl})$ vuosina 1999 - 2006 EU -raja-arvon ylittäviä pitoisuuksia DON:n osalta on ollut 18 kpl. Mikäli tarkastellaan ainoastaan kauranäytteiden DON -pitoisuuksia, raja-arvon $1750 \mu \mathrm{g} / \mathrm{kg}$ ylityksiä on ollut 11 kpl tutkituista 279 näytteestä. Kauranäytteistä lastenruoan raja-arvon $200 \mu \mathrm{g} / \mathrm{kg}$ alittavia näytteitä on ollut $164 \mathrm{kpl}$. Kaura on viljoistamme selvästi herkin Fusarium -tartunnalle ja toksiinien muodostumiselle. Lisäksi rehuohralla ja kevätvehnällä on havaittu raja-arvon ylityksiä.

\section{Johtopäätökset}

Yhteenvetona turvallisuustietoseurannan tuloksista voidaan todeta, että hometoksiinien hallinnassa tärkeintä on siemenen kunnostus ja peittaus, viljelykierto, sadonkorjuun ajoitus ja viljan kuivaus. Myöhäinen lajike lisää toksiiniriskiä, koska kasvukauden venyminen pitkälle loppukesään lisää epävarmuutta sadonkorjuuajan säästä. Lakoontuneessa kasvustossa riski hometoksiinien muodostumiseen kasvaa. Viljan huolellinen lämminilmakuivaus alle $14 \%$ :iin myös hyvinä vuosina on parhaita keinoja hallita hometoksiiniriski. Tutkimustulokset kuorinnan ja lajittelun vaikutuksesta ovat myös lupaavia. Seurantatutkimuksen tuloksiin perustuen on keväällä 2007 julkaistu Vilja-alan yhteistyöryhmän toimesta myös viljelijäopas hometoksiiniriskin hallintaan. Hometoksiinien hallinnassa korostetaan ammattitaitoisen viljelyn merkitystä ja vahvaa vilja-alan toimijoiden yhteistyötä. Turvallisuustietoseuranta jatkuu nykyisellä kokoonpanolla ja tähän mennessä hyväksi havaittujen käytäntöjen mukaisesti. Seurantatutkimusta kehitetään pro -aktiiviseksi ottamalla käyttöön kasvukauden aikaisten kasvustonäytteiden sieni- ja toksiinimääritykset sekä kehittämällä pikamenetelmät ennakoivan, reaaliaikaisen ja nopean tiedon varmistamiseksi.

\section{Kirjallisuus}

Peltonen, S., Hietaniemi V., Rämö, S., Koivisto, T., Kartio M. ja Varimo, K. 2000-2006.

Turvallisuustietoseurannan vuosiraportit. MMM Vilja-alan yhteistyöryhmä / Turvallisuustyöryhmä, Helsinki.

MMM Vilja-alan yhteistyöryhmä / Turvallisuustyöryhmä, www.fingrain.fi 2007. Helsinki.

Punahomeet viljassa: Viljelytekniset toimenpiteet hometoksiiniriskin pienentämiseksi.

MMM Vilja-alan yhteistyöryhmä / Turvallisuustyöryhmä, www.fingrain.fi 2006. Helsinki. Viljan hyvät tuotanto- ja varastointitavat.

Maa- ja metsätalousministeriö, www.fingrain.fi 2007. Helsinki. Kansallinen viljastrategia 2006 - 2015. 